\title{
Determination of the Endocrine Disrupter Bisphenoi-A in the Blood of Uremia Patients Treated by Dialysis
}

\section{H. Shintani ${ }^{1 *}$ and F. Hayashi ${ }^{2}$}

${ }^{1}$ School of Science, Chuo University, 1-13-27, Kasuga, Bunkyo, Tokyo 112-0003, Japan

${ }^{2}$ Health care facility of Namiki hospital. 2-10-22, Uchidabashi, Minamiku, Nagoya, Japan

\begin{abstract}
Summary
Automated solid-phase extraction (SPE) then high-performance liquid chromatography have been studied for determination of the endocrine disrupter bisphenoi-A (BPA) in blood. Electro chemical detection was used for selective and sensitive detection of BPA. Determination of BPA in the blood of uremia patients treated by dialysis has not yet been reported. Acidified blood and acidified SPE eluent were used to suppress the ionization of BPA and thus retain the compound on a C-18 column. Because artificial dialysis can be performed for periods longer than 40 years, for reasons of safety the amount of BPA migrating from the artificial dialyzer into the blood of a uremia patient was compared for different sterilization methods and for different artificial dialyzers manufactured from different materials.
\end{abstract}

Keywords: Column liquid chromatography; Solid-phase extraction; Dialysis; Bisphenol-A

\section{Introduction}

Bisphenol-A (BPA), used to prepare polycarbonates and polysulfones, materials used in the manufacture of medical devices and dental materials, is an endocrine disrupter [1-8]. Because polysulfone is considered to be a biocompatible material it has recently been used to manufacture medical devices in contact with blood; polycarbonate and polysulfone are used in the manufacture of the housing and the hollow fiber material, respectively, of artificial dialyzers. Even if the amount of BPA leached from these components is low, its endocrine-disrupting function will be hazardous to uremia patients, because they might be exposed for periods of more than 40 years. It is, therefore, necessary to monitor how much BPA can migrate to the body fluids of uremia patients.

Polyacrylonitrile and poly(methyl methacrylate) are also regarded as biocompatible polymers, but the migration of the toxic and hazardous monomers acrylonitrile and methyl methacrylate must also be monitored. The author has previously described migration of toxic compounds from poly(methyl methacrylate), polycarbonate, and polysulfone used to manufacture the composite used in dental materials [9-13]. Although the selective determination of methyl methacrylate monomer from poly(methyl methacry.late), and the migration of the compound from poly(methyl methacrylate) were described, migration of BPA from polycarbonate and polysulfone was not studied [9]. Organic solvent extraction of BPA from polycarbonate and polysulfone has also been described [10], but migration of BPA to the blood of uremia patients treated with an artificial dialyzer containing of polycarbonate or polysulfone components has not been studied.

The author has, therefore, conducted this study to assess the risk to uremia patients of exposure to BPA during treatment by artificial dialysis.

\section{Experimental}

\section{Materials}

Reagents used were special or high-performance liquid chromatography (HPLC) grade. The artificial dialyzers used were from
Asahi medical (Tokyo, Japan), Tore (Shiga, Japan), Kawasumi (Ohita, Japan), and Terumo (Kohfu, Japan). The hollow fiber materials of these instruments are manufactured from polysulfone. The housing materials of the dialyzers are manufactured from polycarbonate, except for those in the dialyzer from Asahi medical, which are manufactured from polystyrene-butadiene copolymer. The method of sterilization used for the Asahi medical and Tore instruments is gamma-ray sterilization at $25 \mathrm{kGy}$; that used for the Kawasumi and Terumo equipment is moist heat sterilization at $121.1^{\circ} \mathrm{C}$ for validation period (i.e., $15-20 \mathrm{~min}$ ).

Blood from uremia patients treated by artificial dialysis was supplied by the hospital at the Namiki Hospital in Nagoya, Japan. During the study dialysis treatment was always performed for $4 \mathrm{~h}$, three times a week, for more than three months consecutively. The four different types of dialyzer were used for four different patients.

\section{Blood pretreatment}

Blood of uremia patients (ca $10 \mathrm{~mL}$ ) was sampled before dialysis and after $4 \mathrm{~h}$ of dialysis treatment, to confirm whether or not BPA in the blood was originating from the dialyzer. After addition of heparin blood was centrifuged at $5000 \mathrm{rpm}$ for $20 \mathrm{~min}$. The supernatant plasma thus obtained was stored under refrigeration at $4^{\circ} \mathrm{C}$; under these conditions it was stable for two weeks.

Before analysis the plasma sample was treated by automated solidphase extraction (SPE) on 1-mL Varian Co. BondElut ${ }^{\mathrm{R}}$ cartridges containing $120 \mu \mathrm{L}(100 \mathrm{mg}) \mathrm{C}-18$ resin. The endcapped C-18 SPE cartridge was conditioned with methanol then water $(3 \mathrm{~mL}$ of each) at a flow rate of $3 \mathrm{~mL} / \mathrm{min}$. Plasma $(1 \mathrm{~mL})$ from the uremia patient was

*Corresponding author: Hideharu Shintani, 1-10-60, Minamidaira, Hino, Tokyo 191-0041 Japan, Tel 042-592-2336; E-mail: shintani@mail.hinocatv.ne.jp Received September 12, 2011; Accepted September 30, 2011; Published October 03, 2011

Citation: Shintani H, Hayashi F (2011) Determination of the Endocrine Disrupter Bisphenoi-A in the Blood of Uremia Patients Treated by Dialysis. Pharm Anal Acta S11:001. doi:10.4172/2153-2435.S11-001

Copyright: (c) 2011 Shintani H, et al. This is an open-access article distributed under the terms of the Creative Commons Attribution License, which permits unrestricted use, distribution, and reproduction in any medium, provided the original author and source are credited. 
applied to the conditioned cartridge at $0.5 \mathrm{~mL} / \mathrm{min}$ and the cartridge was rinsed with water $(1 \mathrm{~mL})$ at $1 \mathrm{~mL} / \mathrm{min}$. BPA was then eluted with $5 \%$ phosphoric acid $(4 \mathrm{~mL})$ at $0.5 \mathrm{~mL} / \mathrm{min}$. Conditioning, rinsing, and elution during SPE were performed under vacuum by means of automated Varian Co. BenchMate ${ }^{\mathrm{R}}$ equipment, otherwise reproducible recovery could not be achieved successfully.

\section{High-Performance Liquid Chromatography with Electro- chemical Detection (HPLC-ECD)}

HPLC was performed with a Hewlett Packard Co. HP $1050^{\mathrm{R}}$ chromatograph equipped with UV detection (Shimadzu, Kyoto, Japan, SPD 2A) and ECD (Yanagimoto, Tokyo, Japan, VMD-501). BPA in the blood of uremia patients was determined by means of ion-suppression chromatography on a $250 \mathrm{~mm} \times 4.6 \mathrm{~mm}$ i. d. endcapped Capcelpak ${ }^{\mathrm{R}}$ C-18-UG 120A column from Shiseido (Tokyo, Japan). Isocratic elution was performed with $3: 1(\mathrm{v} / \mathrm{v}) 10 \mathrm{mM}$ ammonium acetate-acetonitrile as mobile phase, at a flow rate was $1 \mathrm{~mL} / \mathrm{min}$; under these conditions the retention time of BPA was $7.6 \mathrm{~min}$. The injection volume was $10 \mu \mathrm{L}$.

Because BPA has two phenolic hydroxyl groups in its chemical structure (Figure 1), it can be detected both by UV absorption (at $235 \mathrm{~nm}$ ) and by electrochemical detection (ECD) at $900 \mathrm{mV}$. ECD is approx. 50 times more sensitive than UV [14]. The order of connection of the detectors at the column outlet should be UV then ECD if the ECD is connected between the column and the UV detector the ECD cell will be damaged by back-pressure from the UV detector.

HPLC-MS was performed by connecting the chromatograph to a Finnigan MAT TSQ $7000^{\mathrm{R}}$ mass spectrometer with atmospheric pressure chemical ionization (APCI). The mass range scanned was between 65 and 800 daltons.

BPA was identified by comparison of its UV spectrum and HPLCmass spectrum (HPLC-MS) with those of standards.

\section{Results and Discussion}

Figure 1 shows the chemical structure of BPA. Figure 2 shows the mass spectrum of BPA obtained by HPLC-MS. Because the spectrum is identical with that of BPA from a database of mass spectra, identification of the compound was satisfactorily confirmed. Figure 3 shows the HPLC chromatogram obtained from BPA after extraction from blood and SPE treatment; ECD was performed at $900 \mathrm{~m} \mathrm{~V}$.

\section{HPLC and automated SPE}

The limit of detection for a signal-to-noise ratio $(\mathrm{S} / \mathrm{N})$ of 2 was $0.002 \mathrm{ng} / \mathrm{mL}$; because accuracy and precision were both within $20 \%$, this can be regarded as an approved detection limit. The limit of determination of BPA by ECD, using the above procedure, was $0.02 \mathrm{ng} /$ $\mathrm{mL}(0.02 \mathrm{ppb})$ in plasma. Use of automated SPE with the BenchMate ${ }^{\mathrm{R}}$ equipment resulted in $99.2 \pm 2.77 \%$ (average $\pm S D ; n=7$ ) recovery of BPA from blood plasma. The response to BP A was linearly dependent on concentration within the range 0 to $80 \mathrm{ng} / \mathrm{mL}$; the correlation

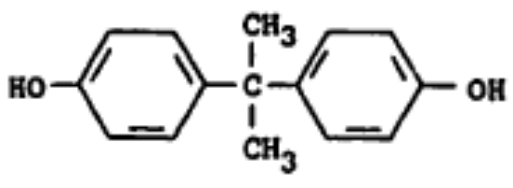

Figure 1: The chemical structure of BPA.

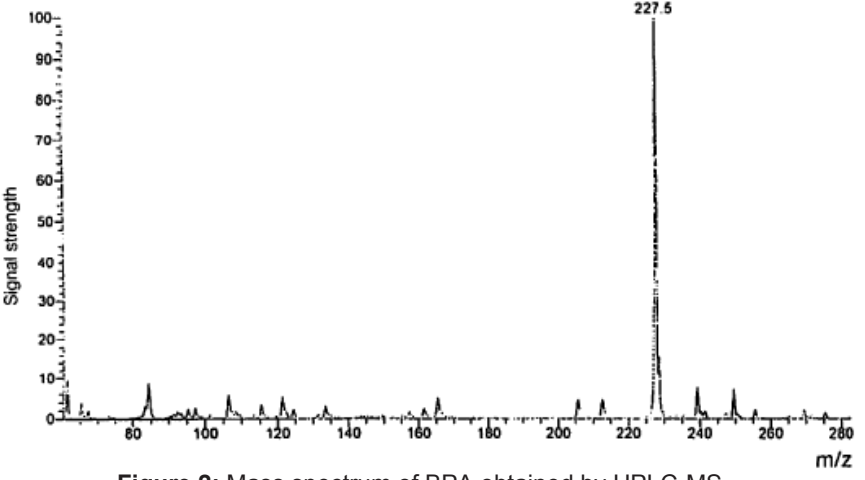

Figure 2: Mass spectrum of BPA obtained by HPLC-MS

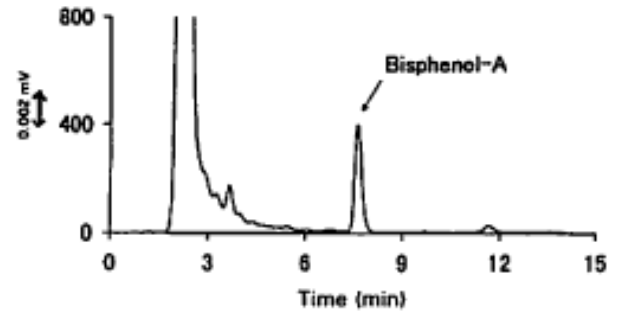

Figure 3: HPLC of BPA $(0.7 \mathrm{ppb})$ from blood after automated SPE treatment (ECD at $900 \mathrm{mV}$ ). The chromatogram obtained from blank plasma before dialysis was identical except that no BPA was eluted; no BPA was detected in the blood of uremia patients sampled before dialysis (N.D. in Table 1).

coefficient was $>0.99$. When SPE was performed manually the recovery varied significantly and was less than that obtained by use of automated SPE. The reproducibility of manual SPE is much inferior to that of automated SPE because accurate pressure control is difficult in the former. Recovery data obtained by manual SPE were thus unreliable.

\section{Amount of BPA migrating to the blood of uremia patients treated with dialyzers made from different materials}

Four patients were treated with four types of dialyzer. The average amounts of BPA migrating into the blood are presented in Table 1 . The average concentrations of BPA in blood treated with the Kawasumi Co. and Terumo Co. dialyzers were 0.2 and $0.7 \mathrm{ppb}(\mathrm{n}=4)$, respectively. The average concentrations in blood treated with the other dialyzers were below limit of determination $(0.02 \mathrm{ppb})$.

The author also conducted an experiment on saline solution (800 $\mathrm{mL}$ ) in accordance with ISO 10993-7 [15]. The results obtained showed that migration of BPA from dialyzers sterilized by autoclaving was approx. 2-5 times greater than from those sterilized by use of gammarays (Table 1). The amounts of BPA migrating into saline solution and blood from the same dialyzer sterilized by the same procedure were also compared. The amount of BPA migrating into saline solution ranged from 0.1 to $0.2 \mathrm{ppb}(\mathrm{n}=4)$ whereas that migrating into blood ranged from 0.2 to $0.7 \mathrm{ppb}$, indicating that migration of BPA, a hy.drophobic compound, into blood might be promoted by the presence of hydrophobic compounds such as lipid, lipoprotein, and phospholipid, etc., in the blood.

More BPA was extracted from polysulfone than from polycarbonate with organic solvents such as methanol, because polysulfone is softer than polycarbonate. Results from dialysis did not, however, always reflect this result. 
Citation: Shintani H, Hayashi F (2011) Determination of the Endocrine Disrupter Bisphenoi-A in the Blood of Uremia Patients Treated by Dialysis. Pharm Anal Acta S11:001. doi:10.4172/2153-2435.S11-001

\begin{tabular}{|l|l|l|l|l|}
\hline $\begin{array}{l}\text { Dialyzer Hollow fiber } \\
\text { Housing }\end{array}$ & $\begin{array}{l}\text { Construction } \\
\text { material } \\
\text { sterilization }\end{array}$ & $\begin{array}{l}\text { Method of BPA } \\
(\mathrm{ppb}, \mathrm{n}=4)\end{array}$ & $\begin{array}{l}\text { Average } \\
\text { amount of }\end{array}$ \\
\hline Asahi medical & PS & PB $^{\mathrm{b}}$ & Gamma-ray & N.D. ${ }^{\mathrm{c}}$ \\
\hline Tore & PS & PC $^{\mathrm{d}}$ & Gamma-ray & N.D. \\
\hline Kawasumi & PS & PC & Autoclaving & 0.2 \\
\hline Terumo & PS & PC & Autoclaving & 0.7 \\
\hline
\end{tabular}

apolysulfone: 'bolystyrene-butadiene copolymer; no migration of BPA was observed, but migration of styrene monomer $(0.2 \mathrm{ppb})$ was detected; "not detected; ${ }^{\mathrm{d}}$ polycarbonate. ${ }^{\mathrm{e}} 121.1^{\circ} \mathrm{C}$ for validated period (normally $15-20 \mathrm{~min}$ ).

Blood of uremia patients (ca $10 \mathrm{~mL}$ ) was sampled before dialysis and after $4 \mathrm{~h}$ of dialysis treatment, to confirm whether or not BPA in the blood was originating from the dialyzer.

Table 1: Materials used in hollow fiber and housing manufacture, method of sterilization, and amount of BPA migrating into the blood of uremia patients.

No migration of BPA was observed from hollow fibers made from polysulfone. Migration of BPA was mostly observed when the header of the dialyzer housing was made from polycarbonate. It is speculated that headers made from polycarbonate might contain more BPA than fibers made from polysulfone; the blood makes contact with both materials. This speculation is supported by the failure to detect BPA originating from the fibers of the Asahi medical dialyzer, which are manufactured from polysulfone (Table 1); stylene monomer from the polystylene header of the Asahi medical Co. dialyzer was, however, detected (Table 1).

From these results it can be concluded that BPA and styrene monomer migrate from the header of the housing, not from hollow fibers. If BPA had also migrated from the Asahi medical dialyzer, it might have originated from the hollow fibers; this possibility was, however, definitely eliminated. The amount of styrene monomer migrating was $0.2 \mathrm{ppb}(\mathrm{n}=4)$. Because the Barcoal hardness of polysulfone was less than that of polycarbonate, it was initially speculated that the origin of migrating BPA might be the polysulfone fibers; this speculation was unfounded because migration of styrene monomer was from the polystyrene housing and no BPA migrated from the polysulfone hollow fibers of the Asahi medical dialyzer.

In the author's experiment to compare formation of methylene dianiline (MDA) from the polyurethane potting material used to connect the hollow fibers and housing, MDA formation and migration were in the order was gamma-ray > autoclaving $>>$ ethylene oxide sterilization [16,17]. For BPA the order of migration, autoclaving $>$ gamma ray $>>$ ethylene oxide sterilization, was not coincided.

\section{Conclusion}

It has been shown that BPA migrates from dialyzers to the blood of uremia patients. The maximum amount migrating was $0.7 \mathrm{ppb}$, much lower than the amount stipulated by food hygiene legislation in Japan (2.5 ppm/day). Dialysis of uremia patients is, however, performed for more than 40 years, so the effect of long-term exposure to many hazardous compounds, in addition to BPA, migrating from the dialyzer must be evaluated. The safety of compounds such as of BPA, MDA, styrene monomer, methyl methacrylate, acrylonitrile, etc., must be investigated. Because the amount of BPA to which uremia patients are exposed will be significant, the safety of long-term exposure for more than 40 years must be studied with care.

\section{References}

1. Lamb J (1997) Em.iron. Health Perspect 105: 273-274.
2. Krishnan AV, Stathis P, Permuth SF, Tokes L, Feldman D (1993) Bisphenol-A an estrogenic substance is released from polycarbonate flasks during autoclaving. Endocrinology 132: 2279-2286.

3. Milligan SR, Balasubramanian AV, Kalita JC (1998) Relative potency of xenobiotic estrogens in an acute in vivo mammalian assay. Environ Health Perspect 106: 23-26

4. Ashby J, Tinwell H (1998) Uterotrophic activity of bisphenol A in the immature rat. Environ Health Perspect 106: 719-720.

5. Nagel SC, vom Saal FS, Thayer KA, Dhar MG, Boechler M, et al. (1997) Relative binding affinity-serum modified access (RBA-SMA) assay predicts the relative in vivo bioactivity of the xenoestrogens bisphenol $A$ and octylphenol Environ Health Perspect 105: 70-76.

6. vom Saal FS, Cooke PS, Buchanan DL, Palanza P, Thayer KA, et al. (1998) A physiologically based approach to the study of bisphenol $A$ and other estrogenic chemicals on the size of reproductive organs, daily sperm production, and behavior. Toxicol Indust Health 14: 239-260.

7. Cagen SZ, Waechter JM Jr, Dimond SS, Breslin WJ, Butala JH, et al. (1999) Normal reproductive organ development in CF-1 mice following prenatal exposure to bisphenol A. Toxicol Sci 50: 36-44.

8. Crews D, Willingham E, Skipper JK (2000) Endocrine disruptors: present issues, future directions. Q Rev Biol 75: 243-260.

9. Shintani H, Tsuchiya T, Hata Y, Nakamura A (1993) Solid phase extraction and HPLC analysis of toxic components eluted from methyl methacrylate dental materials. J Anal Toxicol 17: 73-78.

10. Shintani HJ (1995) Liq Chromatogr 18: 613-626.

11. Shintani HJ (1998) Liq Chromatogr 21: 2297-2312.

12. Shintani HJ (1992) Liq Chromatogr 15: 1315-1335

13. Shintani, H (1998) In Adsorption and its Application in Industry and Environmental Protection: Dabrowski. A. Ed Elsevier Science Amsterdam.

14. Shintani H (1989) Fresenius J Anal Chem 333: 637-640.

15. ISO/TC 194, Biological Evaluation of Medical Devices.

16. Shintani H (1995) The relative safety of gamma-ray, autoclave, and ethylene oxide gas sterilization of thermosetting polyurethane. Biomed Instrum Technol 29: 513-519.

17. Shintani H (1995) Rad Phys Chem 46: 377-381. 